\title{
CARCINOMA EPIDERMOIDE DE URETRA Y GLANDE ¿DOS TUMORES INDEPENDIENTES?
}

\author{
D. PASCUAL REGUEIRO, Á. GARCÍA DE JALÓN MARTÍNEZ, M.Á. TRÍVEZ BONED, \\ P. GIL MARTÍNEZ, J. AZÚA ROMEO*, L.Á. RIOJA SANZ
}

*Departamento de Urología y Anatomía Patológica. Hospital Universitario Miguel Servet. Zaragoza.

Actas Urol Esp. 28 (10): 781-784, 2004

\section{RESUMEN}

CARCINOMA EPIDERMOIDE DE URETRA Y GLANDE ¿DOS TUMORES INDEPENDIENTES?

Un varón de 64 años fue tratado en nuestro hospital por presentar una gran tumoración en el glande peneano.

Durante el acto quirúrgico se detectó otra neoformación en la uretra.

El estudio microscópico mostró un carcinoma epidermoide concomitante en glande peneano y uretra sin tejido afectado entre ambos tumores.

PALABRAS CLAVE: Carcinoma epidermoide. Tumor uretral.

\section{ABSTRACT}

EPIDERMOID CARCINOMA OF THE URETHRA AND GLANS PENIS TWO INDEPENDENT TUMORS? A 64 years-old man is treated in our hospital presenting a big tumor in glans penis. During the surgical act, another neoplasm is detected in the urethra.

The microscopic study showed a concomintant epidermoid carcinoma of glans penis and urethra with non-affected tissue between both tumors.

KEYWORDS: Epidermoid carcinoma. Urethral tumor.

$\mathrm{P}$ esentamos un caso clínico en el cual coinciden en el tiempo dos carcinomas epidermoides, uno uretral y otro de glande en el que el estudio anatomopatológico no pudo descartar la independencia de ambas.

Tanto las tumoraciones peneanas como los uretrales son neoplasias altamente infrecuentes lo que hace del caso una situación excepcional

\section{CASO CLÍNICO}

Paciente varón de 64 años que acude al Servicio de Urgencias de nuestro hospital remitido por su urólogo del ambulatorio al cual había acudido a consultar por la aparición de una ulceración en la piel prepucial de varios meses de evolución y dificultad para la micción con importante disuria y chorro miccional fino.
El paciente no presentaba ningún antecedente de interés a reseñar, y en el plano urológico únicamente relataba cólicos renales expulsivos en la juventud, y nunca había llevado control por el urólogo.

Llamaba la atención la sensación de gravedad del paciente, presentando un mal estado general con pérdida de peso en los últimos meses y con una astenia manifiesta.

La exploración puso de manifiesto una fimosis puntiforme, responsable de su sintomatología miccional, con una induración manifiesta de consistencia pétrea de todo el glande con aparente indemnidad del resto del pene.

A nivel inguinal eran manifiestas las adenopatías bilaterales. 
Se realizó un estudio de extensión consistente en una radiografía de tórax, que resultó normal, y una TAC que confirmó la afectación ganglionar inguinal bilateral, sin otros hallazgos a nivel abdominal.

Dado la afectación del estado general y la clínica miccional se planteó una cirugía paliativaconservadora

$\mathrm{El}$ paciente fue intervenido dos días después. Durante la intervención se realizó en primera instancia una postectomía para poder explorar el glande. Éste apareció completamente desestructurado convertido en una masa de aspecto vegetante y friable en la cual resultaba difícil identificar el meato uretral.

Dado que la afectación quedaba circunscrita al glande se planteó en principio una penectomía parcial. Sin embargo, durante la exploración del resto del pene se identificó una lesión redondeada e indurada a nivel de uretra. Ante la duda razonable de que se tratara de otra neoplasia, se incidió sobre la uretra mandando una cuña de la lesión para estudio peroperatorio.

El resultado anatomopatológico resultó ser un carcinoma epidermoide de la uretra peneana.

Ante esta situación se realizó una penectomía subtotal por debajo de la lesión uretral con conservación de un pequeño muñón (Fig. 1).

$\mathrm{El}$ paciente fue dado de alta dos semanas después siendo su evolución posterior mala con progresión de su enfermedad y falleciendo a los seis meses de la intervención.

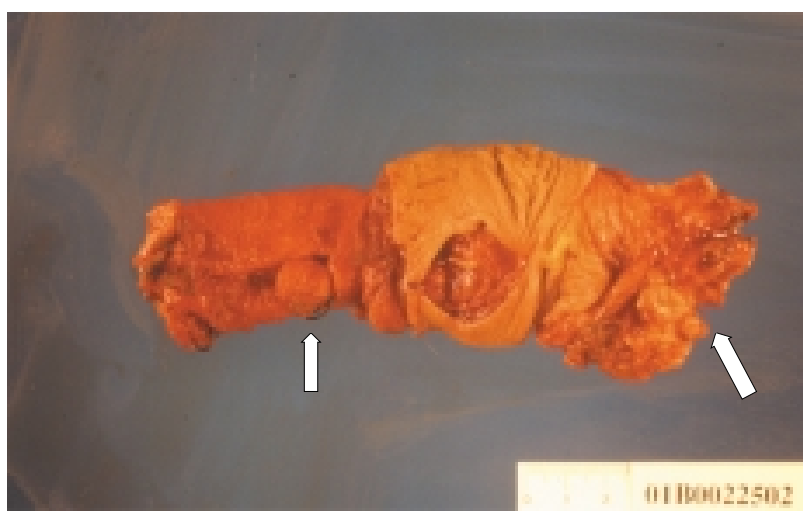

FIGURA 1. Pieza quirúrgica de penectomia subtotal. La flecha grande señala la tumoración del glande de aspecto vegetante. La flecha pequeña muestra la lesión redondeada de menor tamaño situada en la uretra peneana.
El estudio microscópico de la pieza quirúrgica mostró un carcinoma epidermoide medianamente-poco diferenciado de glande contactando con cuerpo esponjoso y un carcinoma epidermoide poco diferenciado en uretra peneana sin afectación de los cuerpos cavernosos.

Se realizaron varios cortes seriados entre ambas lesiones sin poder identificarse continuidad entre ambas lesiones y sin apreciarse invasión vascular ni linfática (Fig. 2).

\section{COMENTARIO}

El cáncer de uretra es una neoplasia excepcional, suponiendo sólo un $1 \%$ de todas las tumoraciones del tracto genitourinario, presentando una relación de 4:1 en la mujer frente al hombre.

Del 50 al $75 \%$ de estas neoplasias se originan en la uretra bulbar ${ }^{1,2}$, correspondiendo el $78 \%$ a carcinomas epidermoides y un $15 \%$ a transicionales, siendo muy raros los adenocarcinomas ${ }^{3}$ que se localizan fundamentalmente en la uretra membranosa.

En la mujer el $70 \%$ son carcinomas epidermoides siendo muy poco frecuentes los transicionales y los adenocarcinomas.

Aunque la localización del tumor guarda gran relación con la extirpe tumoral, recordemos que la uretra anterior tiene un recubrimiento epitelial escamoso y la uretra posterior de tipo transicional, se han descrito tumores de extirpe urotelial incluso en la fosa navicular ${ }^{4}$.

Las neoplasias de pene constituyen menos de un $1 \%$ de todas las neoplasias malignas en el hombre, siendo el carcinoma de pene la más frecuente de todas ellas ${ }^{5,6}$.

$\mathrm{El}$ pudor, la ignorancia por parte del paciente o el tratamiento inadecuado o mala identificación de las lesiones hacen que entre el 10 y el $50 \%$ de los diagnósticos se realicen con más de un año de demora, contribuyendo a la extensión local o a distancia de las lesiones, disminuyendo las posibilidades de curación ${ }^{7-9}$.

La historia natural de los carcinomas escamosos de pene es la progresión local con invasión de las distintas estructuras peneanas, cuerpo de pene, cuerpo esponjoso y uretra y 


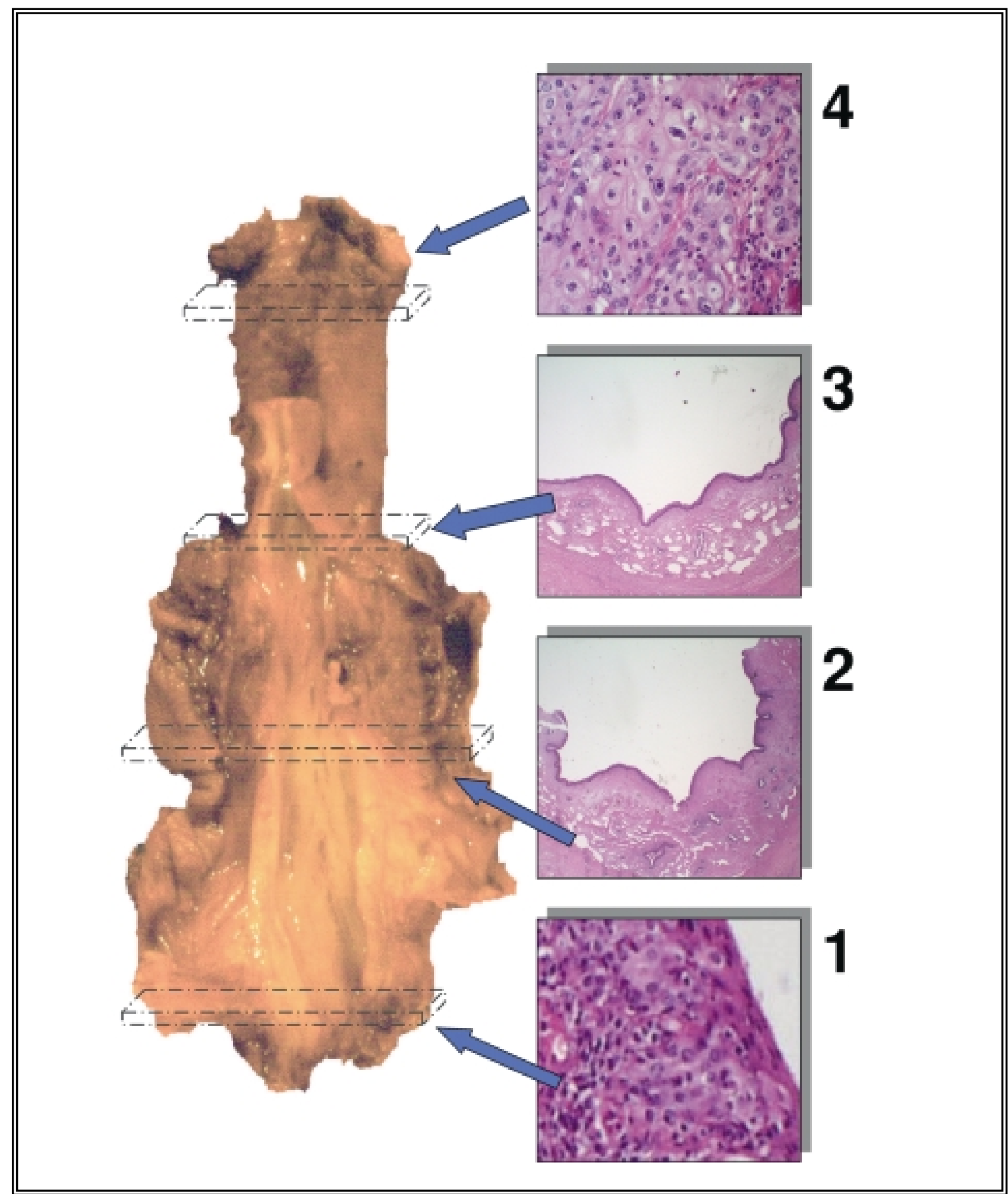

FIGURA 2. Sección longitudinal de pene, abierto por uretra, en el que se demuestra histológicamente, la presencia de dos carcinomas escamosos concomitantes, en glande y uretra respectivamente, pero sin continuidad microscópica entre ambos.

En las microfotografias se destacan ambas neoplasias (1 y 4), asi como se demuestra la ausencia de conexión con los cortes seriados cada $0,3 \mathrm{~cm}$, de los que presentamos dos imágenes representativas (2 y 3) en los que se aprecia un epitelio dentro de la normalidad. 
cuerpos cavernosos, y la progresión a distancia, ya sea vía linfática con afectación de las cadenas ganglionares inguinales, o por vía hematógena dando metástasis en otros órganos de la economía.

En el caso que nos ocupa tenemos dos infrecuentes tumoraciones que aparecen sincrónicamente en el mismo paciente ${ }^{10}$.

El estudio anatomopatológico establece una clara separación, tanto macroscópica como microscópica entre ambas neoformaciones, que no obstante, no puede descartar completamente la progresión por contigüidad de una de ellas a través de la rica vascularización del cuerpo esponjoso peneano.

A pesar de la importante afectación ganglionar inguinal que presentaba el paciente en el momento del diagnóstico, en los múltiples cortes seriados realizados no se pudo demostrar una invasión vascular ni linfática que confirmen o descarten completamente una progresión por continuidad.

Podemos concluir pues, en la coincidencia en el tiempo de dos lesiones neoplásicas de extirpe epitelial, separadas por un tejido sin afectación tumoral, no pudiendo establecer o desestimar claramente una progresión por continuidad desde una de ellas.

\section{REFERENCIAS}

1. Urrutia J, Machuca J, Tallada M et al. Epidermoid carcinoma of the male urethra. Our experience in 5 cases. Arch Esp Urol 1995 May;48(4):355-363.

2. Llorente Abarca C, González- Chamorro F, Domínguez Franjo P. En Luis Resel Estévez y Jesús Moreno Sierra. Tratado de Oncología. Sanidad y Ediciones S.L. 2003. Tomo II Capítulo 86 págs 1093-1100.

3. Hopkins S, Nag S,Soloway M. Primary male carcinoma of the urethra. Urology 1984;23:128-133

4. Steele GS, Fielding JR, Renshaw A, Loughlin KR. Transitional cell carcinoma of the fossa navicularis. Urology 1997;50:792-795.

5. Resel Folkersma LE, Marrero Dominguez R, Ramírez Rodríguez F. En Luis Resel Estévez y Jesús Moreno Sierra. Tratado de Oncologia. Sanidad y Ediciones S.L. 2003. Tomo II Capítulo 82 págs 1057-1069.

6. Gursel EO, Georgountzos C, Usón AC, Melicow MM, Veenema RJ. Penile cancer. Urology 1973;1(6):569.

7. Ornellas AA, Seixas AL, Marota A, Wisnescky A, Campos F, de Morales JR, Surgical treatment of invasive squamous cell carcinoma of the penis: retrospective análisis of 350 cases. J Urol 1994; 15(5): 1244

8. Cubilla A.L, Barreto J, Caballero C and cols. Pathologic features of epidermoid carcinoma of the penis. A prospective study of 66 cases. Am J Surg Pathol 1993 Aug;17(8):753-763.

9. Anderson K.A, McAnich J.W. Primary squamous cell carcinoma of the male urethra. Urology $1984 \mathrm{Feb} ; 23(2): 134-40$

10. Bernstein G, Forgaard D.M, Miller J.E. Carcinoma in situ of the glans penis and distal urethra. J Dermatol Surg Oncol 1986 May;12(5):450-455.

Dr. D. Pascual Regueiro

Avda. Compromiso de Caspe 27-29, 2ํㅜ A

50002 Zaragoza

(Trabajo recibido el 15 diciembre de 2003) 